\title{
Novel mutations A210G and L15Q TBX5 gene in the patients with non-syndromic congenital defects of the heart septal
}

\author{
fariborz soheili ${ }^{1}$, Ragnar Vilmundarson ${ }^{1}$, and Zahra Jalili ${ }^{2}$ \\ ${ }^{1}$ University of Ottawa Heart Institute \\ ${ }^{2}$ Kermanshah University of Medical Sciences
}

May 18, 2020

\begin{abstract}
The TBX5 transcription factor plays an important role during morphogenesis and development of the heart. Mutations in this gene often lead to Holt-Oram syndrome (HOS). This study identified mutations in patients with non-syndromic congenital heart defects (CHD). Screening for mutations TBX5 gene in non-syndromic CHD, including 100 patients with a septal defect and 50 healthy subjects as controls were performed by the technique of high-resolution melt (HRM). Exons were sequenced for samples that showed HRM curve differences compared to controls. Structural stability and pathogenic potential of mutated protein were evaluated by bioinformatics analysis. HRM curve analysis showed that the curves of three samples deviated from the curves of controls. Sequencing showed three heterozygous missense mutations including two novel mutations NM_000192.3:c.44T >G, (p.L15Q), NM_000192.3c.629C >G (p.A210G) and a known mutation NM_000192.3:c.331G>T (p.D111Y). The PolyPhen-2 software predicted the p.D111Y and p.A210G substitutions to be disease-causing and p.L15Q as possibly benign, while protein structural stability analysis by MUpro and DynaMut suggested that these mutations reduce stability and increase the flexibility of the protein. This study presents two novel missense mutations within the TBX5 gene that may be causal for non-syndrome CHD.
\end{abstract}

\section{Introduction}

Molecular regulation of the development of the cardiovascular system is a complex process whose defect leads to abnormalities in the heart. Therefore, congenital heart disease is common because defects in various parts of the heart, such as the atrium, ventricle, or cardiovascular system lead to the disease (Lin, Lin, Chen, Zhou, \& Chang, 2012). The primary septum of the heart is formed between days 27 and 37, and defects in its formation lead to either atrial septal defects (ASD) or ventricle septal defects (VSD) (Gittenberger-de Groot, Calkoen, Poelmann, Bartelings, \& Jongbloed, 2014). The prevalence of ASD is 7 per 10,000 births and women have double the prevalence of men (Fahed, Gelb, Seidman, \& Seidman, 2013; Hoffman \& Kaplan, 2002). The defects of the ventricular septal affecting the membrane or musculature of the septum are the most common congenital anomaly of the heart, occurring at a rate of 12 per 10,000 births (Bhatt et al., 2015).

Gene expression in the pathway of heart development is regulated by multiple transcription factors. Members of the T-box gene family (Tbx) are essential for normal heart development (Zhu et al., 2017). The Tbx5 gene consists of 9 exons with exons 2 to 9 coding the protein. The gene is located at $12 \mathrm{q} 24.1$ in the human genome and encodes a transcription factor that contains a highly conserved DNA binding motif composed of 181 amino acid residues called the T-box or T-domain (Liu et al., 2016; Stirnimann, Ptchelkine, Grimm, \& Müller, 2010). In precursor cells, TBX5 acts with GATA4 and NKX2-5 to activate a large number of genes involved in cardiac specialization (Granados-Riveron et al., 2012; van Weerd \& Christoffels, 2016). 
Subsequently, the expression of TBX5 is limited to the atrium and left ventricle, and the ventricle septal forms on the border between the cells which express TBX5 and those that do not (van Weerd \& Christoffels, 2016). TBX5 competes with TBX20, which is in the right ventricle (Brown et al., 2005). If the TBX5 expressing region is misplaced, the ventricular septal is formed in this new region. Also, TBX5 is important in the formation of upper human organs and its mutation causes Holt-Oram syndrome (HOS) (Basson et al., 1999; Nimura \& Kaneda, 2016). Thus, the transcription factor of the homeobox TBX5, expressed during heart formation, acts as an important regulator and plays a vital role in activating the genes which cooperate in the formation of the right and left heart (Fujita et al., 2017).

Many studies have shown that mutations in the TBX5 gene mainly result in HOS. For example, the study by Postma et al. showed that a Gly125Arg mutation leads to a novel function in the TBX5 protein and affects the development of other organs, leading to the above-mentioned syndrome (Postma et al., 2008). Also, studies by Dressen et al. showed that the Pro85Thr mutation in this protein resulted in this syndrome due to a severe decrease in the activation of other promoters (Dressen et al., 2016). Other studies, such as Basson and Granados-Riveron, showed that the G80R and D111Y mutations led to a non-syndromic malformation of the cardiac septum (Basson et al., 1999; Granados-Riveron et al., 2012). Also, mutations in this gene lead to non-syndromic diseases such as atrial fibrillation (Baban et al., 2014; Guo et al., 2016; Ma et al., 2016). The numerous mutations leading to HOS and other varied clinical symptoms point to the importance of the TBX5 gene and the complexity and variation of the gene regulation it participates in.

The purpose of this study was to find mutations in the TBX5 gene that are involved in the development of non-syndromic cardiac defect phenotypes. Therefore, in this study, screening of these gene mutations in patients with congenital non-syndromic defects of heart septal using high resolution melt (HRM) technique was done in Kurdish people.

\section{Materials and Methods}

\section{Patients}

In this descriptive study, TBX5 gene mutations in patients with ASD and VSD were investigated in 100 cases of congenital heart disease in two hospitals, the Sanandaj Tohid Hospital and Kermanshah Cardiovascular Center. The target Kurdish population consisted of 50 healthy controls who had been admitted to hospital (with no history of familial disease and who showed no cardiac abnormality by echocardiogram ) and 100 cases (62 females and 38 male) of non-syndromic patients including 57 patients with VSD (42 membranous, 14 muscular, 1 conal septal), 39 patients with ASD (36 ostium secundum, 2 sinus venosus, 1 without information) and four patients possessing AVSD (Atrioventricular) (Table 1).

\section{Extracting Genomic DNA}

Genomic DNA was extracted from whole blood by AccuPrep(r) Genomic DNA Extraction Kit from Bioneer Corporation, South Korea.

\section{Real Time PCR and HRM Analysis}

In order to replicate the coding regions of the TBX5 gene (exons 2-9) specific primers for the reference sequence NM_000192.3 and NG_007373.1 were designed in NCBI using CLC Workbench 5.5 software. Gene Reference Sequence ID is LRG_670 (Table 2). The intron/exon boundary (exons 2 to 8) and exon 9 (containing 2177bp), its 575bp component, which is part of the coding region, was considered for the design of the primer. In this study, the Rotor-Gene 6000 (Corbett Research) and 2x QuantiFast SYBR(r) Green kits were used. In order to optimize the PCR reaction as well as HRM, the PCR reaction was performed for all primers under the same conditions as follows: $95 \operatorname{deg} \mathrm{C}$ for 5 minutes and initial denaturation and 40 
cycles of $95 \operatorname{deg} \mathrm{C}$ for 10 seconds and $60 \operatorname{deg} \mathrm{C}$ for 30 seconds and the HRM step from $72 \operatorname{deg} \mathrm{C}$ to $95 \operatorname{deg} \mathrm{C}$, including an increase in temperature of $0.1 \mathrm{degC}$ per second. At first, 10 healthy individuals were identified as sequencing controls and were used as control (wild type) for HRM.

\section{Sequencing}

Patient samples were grouped according to the HRM curve and samples whose melting patterns differed from healthy subjects or controls (Figure 1) were sequenced. Also, 25 samples of patients and 25 controls with normal curves were randomly selected for sequencing. The sequencing of PCR products by ABI 3730XL DNA Analyzers was performed by Bioneer (South Korea) and the results were analyzed using the CLC main workbench.

\section{Predict structural stability of mutation}

The prediction of the structural stability of a protein derived from amino acid mutation was performed based on energy changes by using the sequence information online at the MUpro site (http://www.ics.uci.edu/ ${ }^{\circ}$ baldig/mutation.html) using the SVM method and the support vector machine and neural network (Cheng, Randall, \& Baldi, 2006; Cheng, Randall, Sweredoski, \& Baldi, 2005).

\section{Potential pathogenicity prediction of TBX5 gene sequence variants using PolyPhen-2}

Potential Pathogenicity of TBX5 sequence variants was tested based on two standard human datasets, HumDiv and HumVar, which are applied by PolyPhen-2 Online (http://genetics.bwh.harvard.edu/pph2) (Figure 3). The HumDiv dataset (Adzhubei et al., 2010) contains 5564 mutations in the UniProtKB database known to cause Mendelian disease and 7,539 DNA variants between human proteins and their closely related mammalian equivalents assumed to be non-damaging. The HumVar dataset (Capriotti, Calabrese, \& Casadio, 2006) consists of 22,196 human disease-causing mutations from UniProtKB and 21,151 neutral mutations that are common human nsSNPs (Non-synonymous single nucleotide polymorphisms) (MAF $>1 \%$ ) with no annotated disease involvement. Note that the HumDiv dataset contains annotated mutations directly associated with human diseases, while the HumVar dataset is more noisy as its neutral mutation subset includes many mildly deleterious alleles (Adzhubei et al., 2010; Plekhanova, Nuzhdin, Utkin, \& Samsonova, 2019).

\section{Changes in vibrational entropy and normal mode analysis}

In order to determine the effects of the mutations in flexible conformations and stability of the protein tbx5 (PDB Id: 5BQD), we also used DynaMut, a consensus predictor of protein stability based on the vibrational entropy changes predicted by ENCoM (an elastic network contact model) which is a coarse grain NMA (normal mode analysis) method that considers the nature of the amino-acids and aids in calculating vibrational entropy changes upon mutations, and the stability changes predicted by graph-based signatures that are used in mCSM program (Rodrigues, Pires, \& Ascher, 2018) (Table 3).

\section{Results}

\section{HRM and Sequencing}

Analysis of HRM curves showed that the curve for three patients varied from the other curve of the sample and healthy subjects (Figure 1). The RefSeq transcript used was NM_000192.3 and 
the mutation was named as following the standard human sequence variant nomenclature using Mutalyzer program (https://mutalyzer.nl/) and VariantValidator (https://variantvalidator.org/) (Supplemen$\operatorname{tary} 1 \mathrm{~A}, 1 \mathrm{~B}, 2 \mathrm{~A}, 2 \mathrm{~B}, 3 \mathrm{~A}$ and $3 \mathrm{~B})$.

The sequencing of these three samples (Figure 2) revealed three mutations involving two novel mutations and a reported mutation. The first Novel mutation NM_000192.3:c.44T $>$ G (NM_000192.3:g.711T $>$ G) (Supplementary1A,1B) was in exon 2 which results in replacing Glutamine amino acid instead of Leucine at position 15 (p.L15Q) in a 19-year-old girl with ASD with pulmonary artery stenosis (PS). The second novel mutation was NM_000192.3c.629C >G (NM_000192.3 g.1296C >G) (Supplementary2A,2B) in exon 6 which (Figure 1) leads to replacement of Alanine with Glycine in place 210 of (p.A210G) in a 11-year-old boy with AVSD atrial and ventricular dysfunction and severe failure three-hinged valve and right and left ventricular hypertrophy. Reported mutation was NM_000192.3:c.331G > T (NM_000192.3:g.998G > T)( (Supplementary3A,3B) in exon 4 causes the replacement of amino acid Tyrosine amino acid Aspartate at position 111 of protein (p.D111Y) in a 32-year-old woman with a large hole in the atrium and ventricular septal (large VASD) as well as patent ductus arteriosus (PDA). No mutations were detected in the control group or other patients.

\section{Structure stability prediction for each mutation}

The results of structure stability prediction for each mutation based on both value and sign (direction) of energy change using SVM and sequence information (delta delta G) showed that all three mutations in this study cause protein instability (Table 3 ). In addition, prediction of the sign (direction) of energy change using SVM and neural network with a smaller sequence window show that these mutations decrease stability (Table 3). Also, predicting the impact of mutations on protein conformation, flexibility and stability by DynaMut showed that the D111Y and A210G mutations cause protein destabilization and an increase in its flexibility (Table 3).

\section{The pathogenic potential of the TBX5 gene variants}

The analysis of results using the PolyPhen-2 software based on HumDiv and HumVar database displayed that D111Y and A210G are deleterious mutations (probably damaging) while L15Q mutation is benign (Table 3). A mutation is found to be probably damaging if the PolyPhen value exceeds 0.908 , possibly damaging if between 0.446 and 0.908 and benign if less than or equal to 0.446 (Table 3 and Figure 3).

\section{The D111Y mutation}

The D111Y mutation located in exon 4 of TBX5 gene and the T-box conserved area of its protein. Here, structural stability prediction showed that D111Y mutation decreases protein stability as well as PolyPhen-2 analysis revealed its pathogenicity (Table 3 and Figure 3 ). This mutation in this study is found with a large defect in the heart septal (large VASD) and patent ductus arteriosus (PDA). DynaMut analysis showed this mutation can effect interatomic interactions of the D111Y mutant residue and can result in destabilization and increase protein flexibility (Table 3 and Figure 4 A). Also, Granados-Riveron et al was discovered this mutation in a patient with double outlet right ventricle, large VASD, and PDA. They by using molecular model of human TBX5 protein free from nucleic acid based on PDB file 2X6U showed that there is salt bridge between the D111 and the K126 residues. The D111Y change disrupts the this salt bridge, as the negatively charged aspartic acid (D) residue is replaced by an uncharged tyrosine residue (9).

\section{L15Q mutation}

The novel mutation Lue15Gln, reported for the first time in this study, is located in the exon 2 of the TBX5 gene. It is a missense mutation that replaced the leucine as nonpolar amino acid at the end of the $\mathrm{N}$ protein TBX5 and out of the T-box motif, with a glutamine amino acid. Although the Lue15Gln mutation occurred outside of the T-box, structural stability prediction of this mutation showed it causes protein instability. On the other hand, although the PolyPhen-2 analysis predicted this mutation is benign, it does reduce the stability of the protein and is found with ASD and PS in this study (Table 3). TBX5 protein crystal 
structures deposited in the Protein Data Bank are incomplete for the first 36 residues, therefore information for L15Q from PDB and PDBJ is unavailable.

\section{A210G mutation}

The role of Ala210Gly mutation, in exon 6, is reported here for the first time and has been identified as a missense mutation in the T-box conserved TBX5 gene. Structure stability prediction showed that this mutation leads to protein instability and it is predicted to be deleterious based on PolyPhen-2 analysis. In this study this mutation is associated with abnormalities in the atrial and ventricular septal defect (AVSD), severe failure of Tricuspid regurgitation (sever TR) and right and left ventricular hypertrophy (LVH, RVH) (Table 3). Also, DynaMut analysis showed this mutation can effect interatomic interactions of the A210G mutant residue and can result in destabilization and increase protein flexibility (Table 3 and Figure 4B).

\section{Discussion}

In the present study, the new missense A210G and L15Q and a previously reported D111Y mutation were detected in the TBX5 gene of three separate patients. These mutations were not observed in healthy subjects or the rest of the patients, all of whom had non-syndromic cardiac septal abnormalities. The prediction of pathogenic mutations with the PolyPhen-2 software showed the probable pathogenicity of A210G and D111Y while predicting the L15Q mutation as a benign mutation. In addition, the prediction of structural stability for these mutations based on the SVM method and a neural network approach online at the MUpro site indicates the role of these mutations in protein structure instability.

Previous studies have shown that mutations in the TBX5 gene do not follow a specific pattern, leading to various syndromic and non-syndromic defects in patients. In addition, it shows the existence of a phenomenon of variability (variable expressivity) in this gene (Dressen et al., 2016). Numerous mutations in this gene result in Holt-Oram syndrome, which includes heart problems and skeletal abnormalities in the hands and arms (Dressen et al., 2016). While the absence of both TBX5 allele (null alleles) usually results in HoltOram syndrome, some patients with missense mutations such as G80R cause non-syndromic anomalies and also minor limb malformations but severe heart malformations(Cheng et al., 2005; Postma et al., 2008). Also, previous studies have shown that mutations in this gene lead to non-syndromic diseases such as atrial fibrillation (Boogerd et al., 2010; McDermott et al., 2005; Wang et al., 2016; Yoshida et al., 2015) or dilated cardiomyopathy(Zhou et al., 2015). Meanwhile, the rate of mutation prevalence in this gene in patients with ASD non syndromes was about 4 in 1000, in VSD about 1 in 1000, and in VASD about 3 in 1000 live births (Chung \& Rajakumar, 2016).

As studies have shown, some mutations such as the Gly125Arg gain-of-function mutation, affect the development of the heart and o15ther organs and cause Holt_Oram syndrome(Basson et al., 1999). Because this mutated protein interacts with other transcription factors involved in the formation of the heart such as NKX2.5, TBX3, and GATA4, they interfere with their ability to activate other genes responsible for cardiac cell differentiation (Postma et al., 2008). The Pro85Thr mutation, which causes Holt-Oram syndrome, leads to a significant decline in the activation of other promoters of the genome (loss of function) compared to the normal state of the protein, but this mutation does not disturb the transmission of this protein to the nucleus (Dressen et al., 2016). Among 192 non-syndromic cardiac patients in China, only a H170D mutation in TBX5 was found, leading to non-syndromic atrial fibrillation as a result of reduced protein activity (Wang et al., 2016). Also, a study of 111 patients with non-syndromic congenital heart defects in Japan showed a mutation in the TBX5 gene in only three patients while their mutations are different from the mutations in the present study, two mutations were malignant and one benign (Yoshida et al., 2015). A similar study conducted in heterogeneous populations of different European countries has shown that among 331 congenital heart disease (CHD) patients, only the D111Y mutation in the TBX5 gene results in non-syndromic cardiac abnormalities (Granados-Riveron et al., 2012). Studies have shown that $70 \%$ of patients with HOS contain abnormalities in the heart and upper limbs due to mutation in TBX5 and inadequate haploid (Boogerd et al., 2010; Cross et al., 2000; McDermott et al., 2005) while the gain of function mutations indicated that this gene leads to abnormalities only affecting heart formation (Baban et al., 2014). In addition, mutations in the 
T-box area and outside it in patients with only non-syndromic coronary heart disease have been reported in previous studies (Baban et al., 2014; Bonachea et al., 2014; Brassington et al., 2003; Fan et al., 2003).

In the present study, mutations were uncovered in the TBX5 gene in patients with non-syndromic VSAD and non-syndromic ASD without any skeletal disorders in the Kurdish population of Iran. For the first time the TBX5 gene in this population has been evaluated in relation to these patients. The previous studies in these patients were performed with the screening of NKX2.5 and GATA4 mutations and while no pathogenesis was detected in NKX2.5 a new mutation was detected in GATA4 (Soheili et al., 2015; Soheili et al., 2018). However, in this research, three mutations in TBX5 gene have been identified that have been implicated in congenital non-syndromic cardiac anomalies and have been discussed under their phenotypic and genotypic relationships.

Our study here has shown that the D111Y mutation decreases structural stability and leads to a possibly pathogenic phenotype. However, Granados-Riveron predicted by structural model when the aspartate acid residue (D) is replaced with an uncharged amino acid such as tyrosine (D111Y), a salt bridge is broken down between K126 and D111. Also, this bridge plays a very important role in the structural change of this protein when attached to DNA. This mutation in this study caused a large defect in the heart septal (large VASD) and patent ductus arteriosus (PDA), while in the Granados-Riveron study, in addition to this clinical symptoms, both main arteries were attached to the right ventricle (DORV) (Granados-Riveron et al., 2012). Therefore, this difference may indicate the appearance of a variable of clinical symptoms in this mutation. The new mutation Lue15Gln, which is reported for the first time in this study, is located in the exon 2 of the TBX5 gene. A missense mutation Lue15Gln replaced the nonpolar amino acid at the end of the N protein TBX5 and out of the T-box motif, by glutamine amino acid. Ghosh et al showed that Amino acids 1-237 of TBX5 are required for DNA binding and removal of residues 1-54 from the full length TBX5 prevented its binding to the DNA target (Ghosh et al., 2001). Therefore, although, the Lue15Gln mutation occurred outside of the T-box and deleterious mutation prediction by PolyPhen-2 showed that is a benign mutation, structure stability prediction revealed that this mutation causes protein instability as well as probably having a negative effect on DNA binding interaction of TBX5, the function of transcription activation of TBX5, or potentially causing the loss of synergistic transcription activity between TBX5 and transcription factors such as NKX2.5. Therefore, this mutation is associated with ASD and PS in this study; however, this mutation requires in vitro or in vivo functional studies to clarify the exact impact on TBX5 protein function. The Ala210Gly mutation was associated with AVSD, TR, LVH, and RVH in this study. This mutation is located in the T-box conserved TBX5 gene and in an alpha helix chain of the DNA binding domain. Structure stability and deleterious mutation prediction in this study revealed that this mutation leads to protein instability and is possibly damaging. Since glycine occurs infrequently in alpha helices, it has more conformational flexibility than the other amino acid residues and results in alpha helix instability and it could have an effect on the interaction between TBX5 with DNA. However, as was the case with D111Y, the Ala210Gly mutation requires in vitro or in vivo functional studies to clarify its effect.

Conclusion : Previous studies have shown that TBX5 gene mutations are common in Holt-Oram syndrome or associated with non-syndromic cardiac abnormalities such as fibroblasts. Based on the results of this study, mutations in this gene can lead to non-syndrome septal heart defects and mutations in TBX5 gene is associated with the variable expressivity.

\section{ACKNOWLEDGMENT}

This work was financed and written based on the research project (Number: 88.26) approved by Kurdistan University of Medical Sciences, Sanandaj, Iran. We thank Dr. Ataolah Haidari head of research and Mr. Fardin Gharibay Financial supervisor of Kurdistan University of Medical Sciences. Also, This research was prospectively reviewed and approved by a duly constituted ethics committee. 


\section{Reference}

Adzhubei, I. A., Schmidt, S., Peshkin, L., Ramensky, V. E., Gerasimova, A., Bork, P., . . Sunyaev, S. R. (2010). A method and server for predicting damaging missense mutations. Nature methods, 7 (4), 248-249.

Baban, A., Postma, A. V., Marini, M., Trocchio, G., Santilli, A., Pelegrini, M., . . . Barnett, P. (2014). Identification of TBX5 mutations in a series of 94 patients with Tetralogy of Fallot.American Journal of Medical Genetics Part A, 164 (12), 3100-3107.

Basson, C. T., Huang, T., Lin, R. C., Bachinsky, D. R., Weremowicz, S., Vaglio, A., . . . Romeo, G. (1999). Different TBX5 interactions in heart and limb defined by Holt-Oram syndrome mutations. Proceedings of the National Academy of Sciences, 96 (6), 2919-2924.

Bhatt, A. B., Foster, E., Kuehl, K., Alpert, J., Brabeck, S., Crumb, S., . . . Karamlou, T. (2015). Congenital heart disease in the older adult. Circulation, 131 (21), 1884-1931.

Bonachea, E. M., Zender, G., White, P., Corsmeier, D., Newsom, D., Fitzgerald-Butt, S., . . . McBride, K. L. (2014). Use of a targeted, combinatorial next-generation sequencing approach for the study of bicuspid aortic valve. BMC medical genomics, 7 (1), 56.

Boogerd, C. J., Dooijes, D., Ilgun, A., Hordijk, R., Van De Laar, I. M., Rump, P., . . . Postma, A. V. (2010). Functional analysis of novel TBX5 T-box mutations associated with Holt-Oram syndrome. Cardiovascular research, cvq178.

Brassington, A.-M. E., Sung, S. S., Toydemir, R. M., Le, T., Roeder, A. D., Rutherford, A. E., . . . Bamshad, M. J. (2003). Expressivity of Holt-Oram syndrome is not predicted by TBX5 genotype. The American Journal of Human Genetics, 73 (1), 74-85.

Brown, D. D., Martz, S. N., Binder, O., Goetz, S. C., Price, B. M., Smith, J. C., \& Conlon, F. L. (2005). Tbx5 and Tbx20 act synergistically to control vertebrate heart morphogenesis.Development, 132 (3), 553-563.

Capriotti, E., Calabrese, R., \& Casadio, R. (2006). Predicting the insurgence of human genetic diseases associated to single point protein mutations with support vector machines and evolutionary information.Bioinformatics, 22 (22), 2729-2734.

Cheng, J., Randall, A., \& Baldi, P. (2006). Prediction of protein stability changes for single-site mutations using support vector machines. Proteins: Structure, Function, and Bioinformatics, 62 (4), 1125-1132.

Cheng, J., Randall, A. Z., Sweredoski, M. J., \& Baldi, P. (2005). SCRATCH: a protein structure and structural feature prediction server.Nucleic acids research, 33 (suppl 2), W72-W76.

Chung, I.-M., \& Rajakumar, G. (2016). Genetics of congenital heart defects: the NKX2-5 gene, a key player. Genes, 7 (2), 6.

Cross, S. J., Ching, Y.-h., Li, Q. Y., Armstrong-buisseret, L., Spranger, S., Lyonnet, S., . . . Leheup, B. (2000). The mutation spectrum in Holt-Oram syndrome. Journal of medical genetics, 37 (10), 785-787.

Dressen, M., Lahm, H., Lahm, A., Wolf, K., Doppler, S., Deutsch, M. A., . . . Ewert, P. (2016). A novel de novo TBX5 mutation in a patient with Holt-Oram syndrome leading to a dramatically reduced biological function. Molecular Genetics 83 Genomic Medicine, 4 (5), 557-567.

Fahed, A. C., Gelb, B. D., Seidman, J., \& Seidman, C. E. (2013). Genetics of Congenital Heart Disease. Circulation research, 112 (4), 707-720.

Fan, C., Duhagon, M., Oberti, C., Chen, S., Hiroi, Y., Komuro, I., . . . Wang, Q. (2003). Novel TBX5 mutations and molecular mechanism for Holt-Oram syndrome. Journal of medical genetics, 40 (3), e29-e29.

Fujita, J., Freire, P., Coarfa, C., Benham, A. L., Gunaratne, P., Schneider, M. D., . . . Zwaka, T. P. (2017). Ronin Governs Early Heart Development by Controlling Core Gene Expression Programs. Cell Reports, 21 
(6), 1562-1573.

Ghosh, T. K., Packham, E. A., Bonser, A. J., Robinson, T. E., Cross, S. J., \& Brook, J. D. (2001). Characterization of the TBX5 binding site and analysis of mutations that cause Holt-Oram syndrome. Human molecular genetics, 10 (18), 1983-1994.

Gittenberger-de Groot, A. C., Calkoen, E. E., Poelmann, R. E., Bartelings, M. M., \& Jongbloed, M. R. (2014). Morphogenesis and molecular considerations on congenital cardiac septal defects. Annals of medicine, $46(8), 640-652$.

Granados-Riveron, J. T., Pope, M., Bu'Lock, F. A., Thornborough, C., Eason, J., Setchfield, K., . . . Feneley, M. P. (2012). Combined Mutation Screening of NKX2-5, GATA4, and TBX5 in Congenital Heart Disease: Multiple Heterozygosity and Novel Mutations. Congenital heart disease, 7 (2), 151-159.

Guo, D. F., Li, R. G., Yuan, F., Shi, H. Y., Hou, X. M., Qu, X. K., . . . Jiang, J. Q. (2016). TBX5 loss-offunction mutation contributes to atrial fibrillation and atypical Holt-Oram syndrome. Molecular medicine reports, 13 (5), 4349-4356.

Hoffman, J. I., \& Kaplan, S. (2002). The incidence of congenital heart disease. Journal of the American college of cardiology, 39 (12), 1890-1900.

Lin, C.-J., Lin, C.-Y., Chen, C.-H., Zhou, B., \& Chang, C.-P. (2012). Partitioning the heart: mechanisms of cardiac septation and valve development. Development, 139 (18), 3277-3299.

Liu, C. F., Brandt, G. S., Hoang, Q. Q., Naumova, N., Lazarevic, V., Hwang, E. S., . . . Petsko, G. A. (2016). Crystal structure of the DNA binding domain of the transcription factor T-bet suggests simultaneous recognition of distant genome sites. Proceedings of the National Academy of Sciences, 113 (43), E6572-E6581.

Ma, J.-F., Yang, F., Mahida, S. N., Zhao, L., Chen, X., Zhang, M. L., . . . Zheng, G.-Y. (2016). TBX5 mutations contribute to early-onset atrial fibrillation in Chinese and Caucasians. Cardiovascular research, 109 (3), 442-450.

McDermott, D. A., Bressan, M. C., He, J., Lee, J. S., Aftimos, S., Brueckner, M., . . . Innis, J. W. (2005). TBX5 genetic testing validates strict clinical criteria for Holt-Oram syndrome. Pediatric research, 58 (5), 981-986.

Nimura, K., \& Kaneda, Y. (2016). Elucidating the mechanisms of transcription regulation during heart development by next-generation sequencing. Journal of human genetics, 61 (1), 5-12.

Plekhanova, E., Nuzhdin, S. V., Utkin, L. V., \& Samsonova, M. G. (2019). Prediction of deleterious mutations in coding regions of mammals with transfer learning. Evolutionary applications, 12 (1), 18-28.

Postma, A. V., van de Meerakker, J. B., Mathijssen, I. B., Barnett, P., Christoffels, V. M., Ilgun, A., . . . Moorman, A. F. (2008). A gain-of-function TBX5 mutation is associated with atypical Holt-Oram syndrome and paroxysmal atrial fibrillation. Circulation research, 102 (11), 1433-1442.

Rodrigues, C. H., Pires, D. E., \& Ascher, D. B. (2018). DynaMut: predicting the impact of mutations on protein conformation, flexibility and stability. Nucleic acids research, 46 (W1), W350-W355.

Soheili, F., Darabi, P., Dahmardeh, F., Heidary, N., Jalili, Z., Fooladi, S., \& Saeid, M. (2015). Nkx2-5 Mutations in Patients with Non-Syndrome Congenital Heart Disease.

Soheili, F., Jalili, Z., Rahbar, M., Khatooni, Z., Mashayekhi, A., \& Jafari, H. (2018). Novel mutation of GATA4 gene in Kurdish population of Iran with nonsyndromic congenital heart septals defects. Congenital Heart Disease . doi:10.1111/chd.12571

Stirnimann, C. U., Ptchelkine, D., Grimm, C., \& Muller, C. W. (2010). Structural Basis of TBX5-DNA Recognition: The T-Box Domain in Its DNA-Bound and-Unbound Form. Journal of molecular biology, 400 (1), 71-81. 
van Weerd, J. H., \& Christoffels, V. M. (2016). The formation and function of the cardiac conduction system. Development, 143 (2), 197-210.

Wang, Z.-C., Ji, W.-H., Ruan, C.-W., Liu, X.-Y., Qiu, X.-B., Yuan, F., . . . Huang, R.-T. (2016). Prevalence and Spectrum of TBX5 Mutation in Patients with Lone Atrial Fibrillation. International journal of medical sciences, 13 (1), 60.

Yoshida, A., Morisaki, H., Nakaji, M., Kitano, M., Kim, K.-s., Sagawa, K., . . . Kato, H. (2015). Genetic mutation analysis in Japanese patients with non-syndromic congenital heart disease. Journal of human genetics .

Zhou, W., Zhao, L., Jiang, J. Q., Jiang, W. F., Yang, Y. Q., \& Qiu, X. B. (2015). A novel TBX5 lossof-function mutation associated with sporadic dilated cardiomyopathy. International journal of molecular medicine, 36 (1), 282-288.

Zhu, T., Qiao, L., Wang, Q., Mi, R., Chen, J., Lu, Y., . . . Zheng, Q. (2017). T-box family of transcription factor-TBX5, insights in development and disease. Am J Transl Res, 9 (2), 442-453.

Table 1. clinical characteristics of the patients with congenital heart septal defect

Total 100 (100)

Gender F: 0.391, P:0.391

Male

Female

Family history F: 0.362, P:0.237

YES

NO

No-information
Table 1. clinical characteristics of the $p$

ASD N (\%)

39 (39)

Gender F: 0.391, P:0.391

$12(12)$

$28(27)$

Family history F: 0.362, P:0.237

29

2

8

\begin{tabular}{llll}
\hline Table 2. TBX5 Primer Sequence & Table 2. TBX5 Primer Sequence & Table 2. TBX5 Primer Sequence & Table 2. TBX5 \\
\hline Ta & Size & Reverse Primer & Forward Prime \\
55 & 218 & TTGTTTTGTTCTGTCCCCGC & ATCTCCCCC \\
53 & 272 & TGCCCCTTTCCTTCCTTC & TGTGTTTTG \\
52 & 278 & CCACTTTTCTCTCTCCCC & TTTCCGCTT \\
52 & 307 & AGGACAAGAGGGAGACA & TCCCAGCTA \\
52 & 311 & CCATTCAGAGGAGCAAAGT & TATCTGGAG \\
54 & 294 & GGTTGCTGCTGGCTTACC & TGGCTTAAT \\
50 & 334 & TACTCCTCACCCCCTCAC & GTTATCTCC \\
52 & 371 & GAGAAGTGCTGGTAGGGTAG & CCAAATAAC \\
52 & 348 & CCTCTCTCTCTCTCTTTCTC & CTACCCTAC \\
\hline
\end{tabular}

\begin{tabular}{|c|c|c|c|c|}
\hline $\begin{array}{l}\text { Table } 3 . \text { TBX2.5 } \\
\text { nonsynonymous } \\
\text { variations } \\
\text { identified in } 57 \\
\text { patients with } \\
\text { VSD, } 39 \text { patients } \\
\text { with ASD and } 50 \\
\text { healthy control }\end{array}$ & $\begin{array}{l}\text { Table } 3 . \text { TBX2.5 } \\
\text { nonsynonymous } \\
\text { variations } \\
\text { identified in } 57 \\
\text { patients with } \\
\text { VSD, } 39 \text { patients } \\
\text { with ASD and } 50 \\
\text { healthy control }\end{array}$ & $\begin{array}{l}\text { Table } 3 . \text { TBX2.5 } \\
\text { nonsynonymous } \\
\text { variations } \\
\text { identified in } 57 \\
\text { patients with } \\
\text { VSD, } 39 \text { patients } \\
\text { with ASD and } 50 \\
\text { healthy control }\end{array}$ & $\begin{array}{l}\text { Table } 3 . \text { TBX2.5 } \\
\text { nonsynonymous } \\
\text { variations } \\
\text { identified in } 57 \\
\text { patients with } \\
\text { VSD, } 39 \text { patients } \\
\text { with ASD and } 50 \\
\text { healthy control }\end{array}$ & $\begin{array}{l}\text { Table } 3 . \text { TBX2.5 } \\
\text { nonsynonymous } \\
\text { variations } \\
\text { identified in } 57 \\
\text { patients with } \\
\text { VSD, } 39 \text { patients } \\
\text { with ASD and } 50 \\
\text { healthy control }\end{array}$ \\
\hline Number & 1 & 1 & 2 & 3 \\
\hline
\end{tabular}




\begin{tabular}{|c|c|c|c|c|}
\hline $\begin{array}{l}\text { Table } 3 . \text { TBX2.5 } \\
\text { nonsynonymous } \\
\text { variations } \\
\text { identified in } 57 \\
\text { patients with } \\
\text { VSD, } 39 \text { patients } \\
\text { with ASD and } 50 \\
\text { healthy control }\end{array}$ & $\begin{array}{l}\text { Table } 3 . \text { TBX2.5 } \\
\text { nonsynonymous } \\
\text { variations } \\
\text { identified in } 57 \\
\text { patients with } \\
\text { VSD, } 39 \text { patients } \\
\text { with ASD and } 50 \\
\text { healthy control }\end{array}$ & $\begin{array}{l}\text { Table } 3 . \text { TBX2.5 } \\
\text { nonsynonymous } \\
\text { variations } \\
\text { identified in } 57 \\
\text { patients with } \\
\text { VSD, } 39 \text { patients } \\
\text { with ASD and } 50 \\
\text { healthy control }\end{array}$ & $\begin{array}{l}\text { Table } 3 . \text { TBX2.5 } \\
\text { nonsynonymous } \\
\text { variations } \\
\text { identified in } 57 \\
\text { patients with } \\
\text { VSD, } 39 \text { patients } \\
\text { with ASD and } 50 \\
\text { healthy control }\end{array}$ & $\begin{array}{l}\text { Table } 3 . \text { TBX2.5 } \\
\text { nonsynonymous } \\
\text { variations } \\
\text { identified in } 57 \\
\text { patients with } \\
\text { VSD, } 39 \text { patients } \\
\text { with ASD and } 50 \\
\text { healthy control }\end{array}$ \\
\hline Location & E6 & E6 & $\mathrm{E} 4$ & $\mathrm{E} 2$ \\
\hline $\begin{array}{l}\text { Nucleotide } \\
\text { changes }\end{array}$ & c. $629 \mathrm{C}>\mathrm{G}$ & c. $629 \mathrm{C}>\mathrm{G}$ & $\mathrm{c} 331 \mathrm{G}>\mathrm{T}$ & c. $44 \mathrm{~T}>\mathrm{G}$ \\
\hline $\begin{array}{l}\text { Amino acid } \\
\text { change }\end{array}$ & p.A210G & p.A210G & p.D111Y & p.L15Q \\
\hline $\begin{array}{l}\text { Type of Cardiac } \\
\text { defects }\end{array}$ & ASD \& PS & ASD \& PS & $\begin{array}{l}\text { Large ASD\& } \\
\text { VSD , PDA }\end{array}$ & $\begin{array}{l}\text { AVSD, TR, LVH, } \\
\text { RVH }\end{array}$ \\
\hline Family history & $\mathrm{N} / \mathrm{A}$ & $\mathrm{N} / \mathrm{A}$ & Yes & Yes \\
\hline $\begin{array}{l}\text { Mutation } \\
\text { novel/report }\end{array}$ & Novel & Novel & 9 & Novel \\
\hline Stability by & Stability by & Stability by & Stability by & Stability by \\
\hline $\begin{array}{l}\text { SVM Confidence } \\
\text { Score }\end{array}$ & Decrease -1.00 & Decrease -1.00 & Decrease -0.260 & Decrease -0.911 \\
\hline $\begin{array}{l}\text { Neural Network } \\
\text { methods }\end{array}$ & Decrease -0.9 & Decrease -0.9 & Decrease -0.550 & Decrease -0.917 \\
\hline $\begin{array}{l}\text { Confidence Score } \\
\text { detal delta G } \\
\text { Score }\end{array}$ & Decrease -1.1 & Decrease -1.1 & Decrease -0.639 & Decrease -1.3 \\
\hline PolyPhen-2 & PolyPhen-2 & PolyPhen-2 & PolyPhen-2 & PolyPhen-2 \\
\hline Result & Result & Result & Result & Result \\
\hline $\begin{array}{l}\text { HumDiv Score: } \\
\text { Sensitivity: } \\
\text { specificity }\end{array}$ & $\begin{array}{l}\text { Benign } 0.0370 .94 \\
0.82\end{array}$ & $\begin{array}{l}\text { Benign } 0.0370 .94 \\
0.82\end{array}$ & $\begin{array}{l}\text { Probably } \\
\text { damaging } 1.00 \\
0.001 .00\end{array}$ & $\begin{array}{l}\text { Possibly } \\
\text { damaging } 0.79 \\
0.850 .93\end{array}$ \\
\hline $\begin{array}{l}\text { HumVar: Score: } \\
\text { Sensitivity: } \\
\text { specificity }\end{array}$ & $\begin{array}{l}\text { Benign } 0.0270 .94 \\
0.58\end{array}$ & $\begin{array}{l}\text { Probably } \\
\text { damaging } 1.00 \\
0.180 .98\end{array}$ & $\begin{array}{l}\text { Probably } \\
\text { damaging } 1.00 \\
0.180 .98\end{array}$ & $\begin{array}{l}\text { Possibly } \\
\text { damaging } 0.50 .82 \\
0.81\end{array}$ \\
\hline $\begin{array}{l}\text { DynaMut } \\
\text { analysis }\end{array}$ & $\begin{array}{l}\text { DynaMut } \\
\text { analysis }\end{array}$ & $\begin{array}{l}\text { DynaMut } \\
\text { analysis }\end{array}$ & $\begin{array}{l}\text { DynaMut } \\
\text { analysis }\end{array}$ & $\begin{array}{l}\text { DynaMut } \\
\text { analysis }\end{array}$ \\
\hline Stability $\Delta \Delta \mathrm{G}$ & $\begin{array}{l}\text { Destabilizing }-0.296 \\
\mathrm{kcal} / \mathrm{mol}\end{array}$ & $\begin{array}{l}\text { Destabilizing }-0.296 \\
\mathrm{kcal} / \mathrm{mol}\end{array}$ & $\begin{array}{l}\text { Destabilizing }-0.260 \\
\mathrm{kcal} / \mathrm{mol}\end{array}$ & $\begin{array}{l}\text { Not available in } \\
\text { PDB }\end{array}$ \\
\hline NMA Based & Destabilizing & Destabilizing & Destabilizing & \\
\hline $\begin{array}{l}\text { Predictions } \Delta \Delta \mathrm{G} \\
\text { ENCoM }\end{array}$ & $-0.135 \mathrm{kcal} / \mathrm{mol}$ & $-0.135 \mathrm{kcal} / \mathrm{mol}$ & $-0.157 \mathrm{kcal} / \mathrm{mol}$ & \\
\hline Flexibility & Increase 0.169 & Increase 0.169 & Increase 0.196 & \\
\hline$\Delta \Delta$ SVib ENCoM & kcal.mol ${ }^{-1} \cdot \mathrm{K}^{-1}$ & kcal.mol ${ }^{-1} \cdot \mathrm{K}^{-1}$ & kcal.mol ${ }^{-1} \cdot \mathrm{K}^{-1}$ & \\
\hline
\end{tabular}

Figure 1 .A) Normalized plots for exon exons 6. The arrow of the mutated curve C> G, c. 629, differs from that of non-mutated specimens. Figure B. Differentiating plots for variation of exon 6.

Figure. 2 (A) Results of the sequencing of nucleotide changes in exon 2 where the mutation c.44 T> A results in a change in the amino acid L15Q B) Results of the sequencing of nucleotide changes in exon 4, which mutations c.331 G> T lead to change The amino acid is D111Y. C) Results of the sequencing of nucleotide changes in exon 6 where mutation c. $629 \mathrm{C}>\mathrm{G}$ leads to alteration of amino acid A210G. 
Figure 3. The pathogenic potential of the TBX5 gene variants by PolyPhen-2. A) Mutation A210G is predicted to be possibly damaging B) Mutation D111Y is predicted to be probably damaging and C) Mutation L15Q is predicted to be benign.

Figure 4. A) Interatomic interactions of the A210G mutant. B) Interatomic interactions of the D111Y mutant. Wild type and mutant are colored in light green and black arrow also represented as sticks alongside the surrounding residues, which are involved on any type of interactions. C) Color definition for bond type.
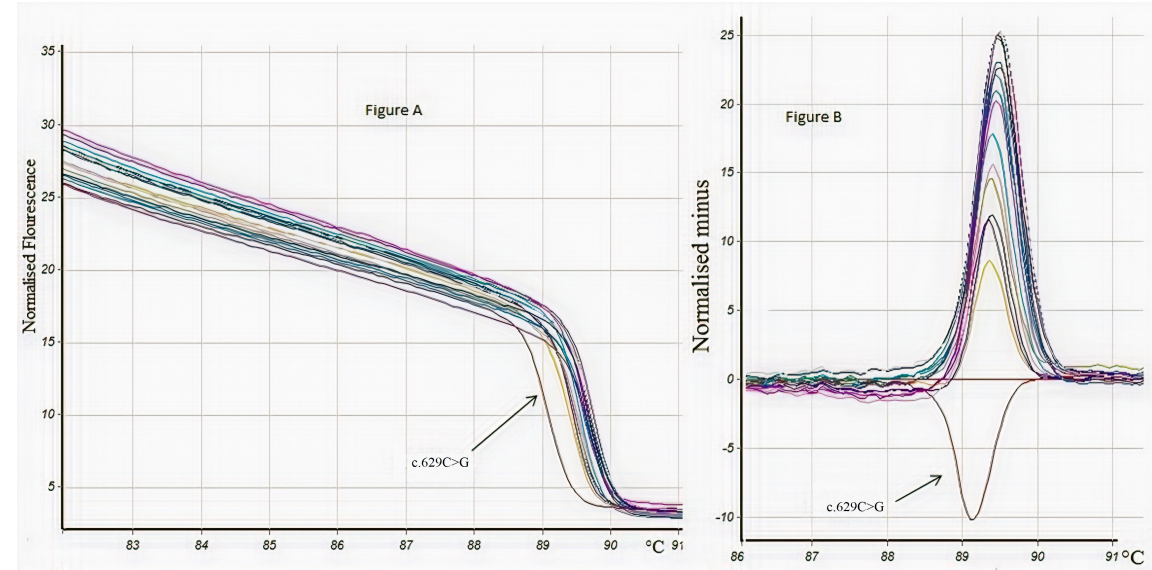

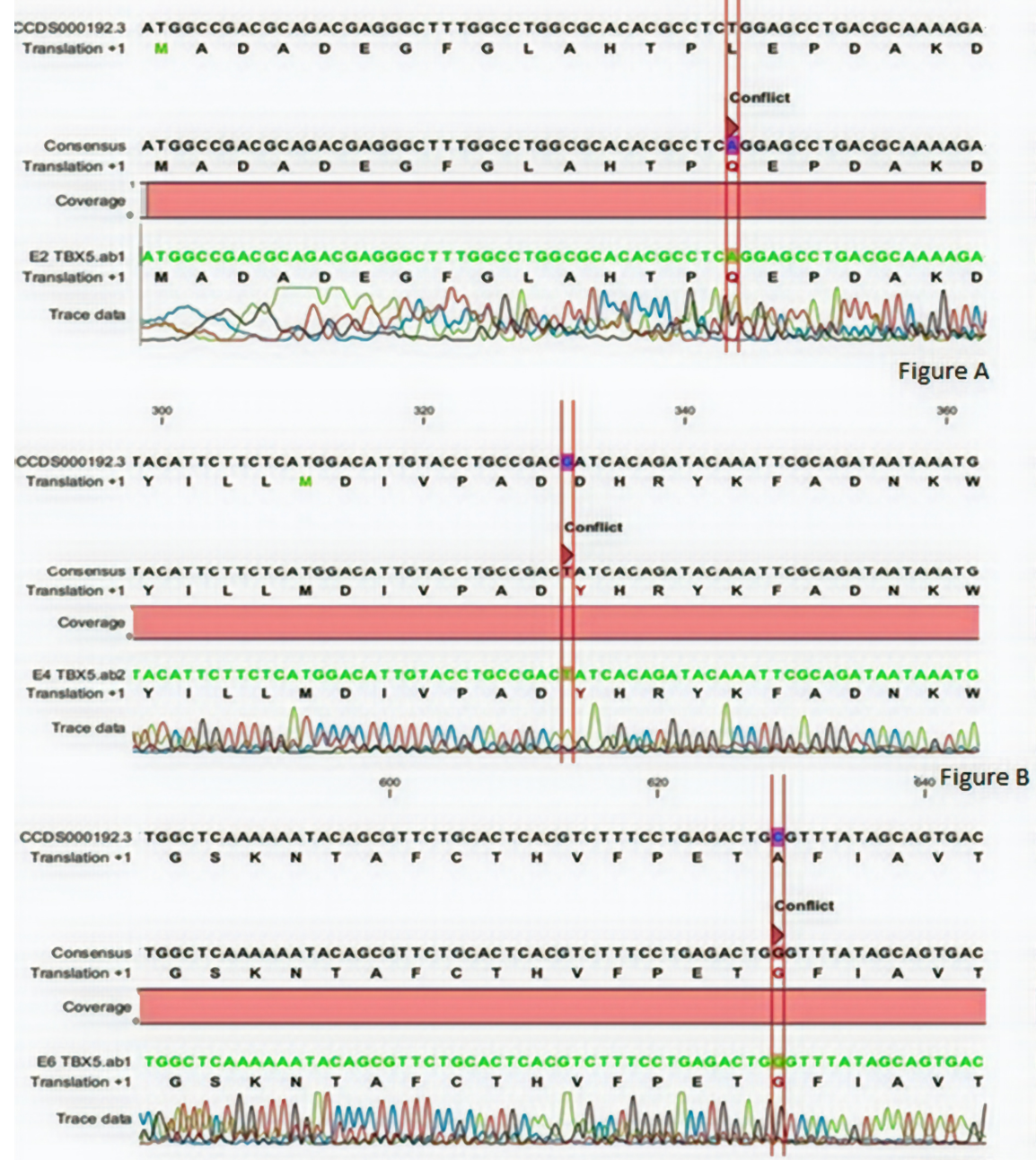

Figure C 
A
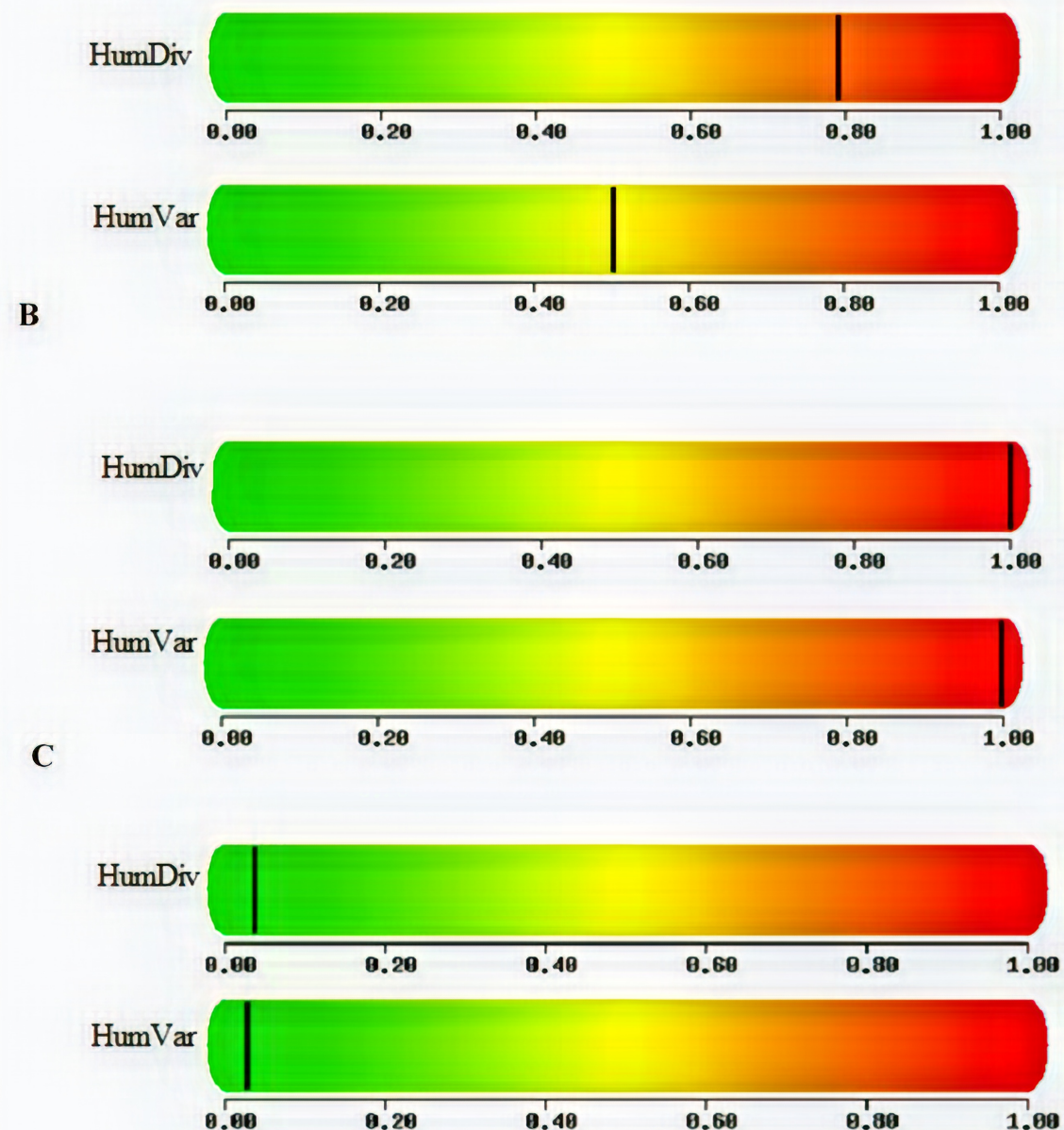

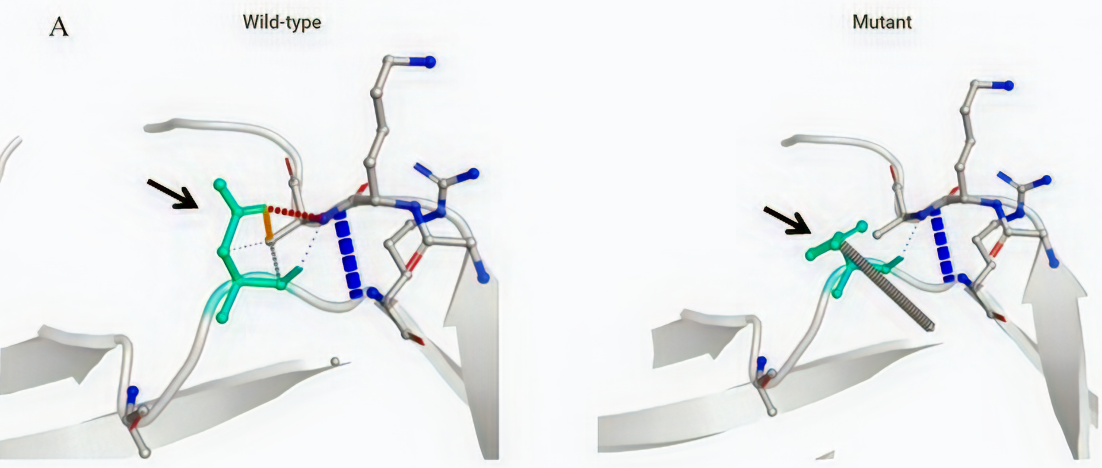

B
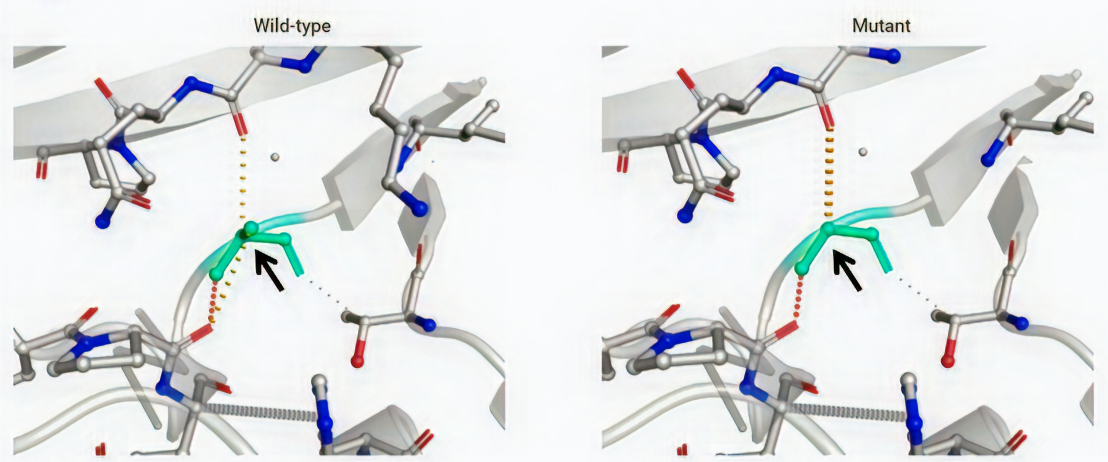

C

\begin{tabular}{|c|c|c|}
\hline Ionic interactions & [ & Hydrogen bonds \\
\hline Metal complex interactions & 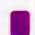 & Water mediated hydrogen bonds \\
\hline Aromatic contacts & $\mathbf{0}$ & Weak hydrogen bonds \\
\hline Hydrophobic contacts & D & Water mediated weak hydrogen bonds \\
\hline Carbonyl contacts & & Halogen bonds \\
\hline
\end{tabular}

